\title{
Thinking Together: A Duoethnographic Inquiry Into the Implementation of a Field Experience Curriculum
}

\author{
Jackie Seidel \\ University of Calgary \\ Laurie Hill \\ St. Mary’s University
}

\begin{abstract}
This paper examines the experiences of two colleagues working in close collaboration over several years to create, implement, and assess an innovative and integrative cohortbased, preservice-teacher, field-experience curriculum in a new Bachelor of Education program. Engaging a duoethnographic narrative approach, this paper both inquires into the experiences of the authors, and traces the complex interrelational work, and personal work that was required to do "good" work together on behalf of preservice students and partners in the "field."

Keywords: field experiences; duoethnography; teacher education; curriculum change

\section{Authors' Note}

Marianne Burgess (Field Experience Coordinator, 2011-2014) presented an early version of this paper with us at CSSE in Victoria in 2013 and has since retired. We offer her our deepest gratitude for the time we spent working together and for her blessings on this paper.
\end{abstract}






\section{Thinking Together: A Duoethnographic Inquiry Into the Implementation of a Field Experience Curriculum}

In fall 2011, the Faculty of Education (now the Werklund School of Education), University of Calgary, implemented a completely revised Bachelor of Education (B.Ed.) program (combined and post-degree). The new B.Ed. program consists of four semesters of coursework, with a school-based field experience in each semester. On the surface, this is a simple story to tell.

A Field Experience Curriculum Director (Jackie Seidel) was appointed by the Dean. A Field Experience Curriculum Development Committee, including members from the university and the field, was then assembled. Over the course of six months, a draft curriculum for the first two semesters was written, diverse partners in the field (teachers, superintendents, principals, teachers' association representatives) were consulted and revisions were made. Two Field Experience Coordinators were hired (Laurie Hill was one) and they joined in the process of implementing the curriculum. The new curriculum was philosophically and structurally different from what had been done previously. What was imagined was ambitious and involved greater levels of collaboration between preservice teachers, partner teachers, and instructors. It felt exciting and a bit risky. Prior to the initial implementation, extensive professional development and orientation were conducted with partner teachers and field instructors. Following the first and second semesters, feedback was gathered from preservice teachers, partners in the field, and instructors. The curriculum was revised, in some cases significantly, by the Field Curriculum Committee, which was also in the process of writing the second year curriculum. The cycle of curriculum development, feedback and implementation continued over several years.

Engaging a duoethnographic approach, this paper goes beyond the simple story and dialogically investigates the complex depths of one particular preservice curriculum creation and implementation experience. Although we do describe some aspects of the new field experience program, the focus and purpose of this inquiry and paper is not to detail the completed or final curriculum, but rather to document and inquire into the lived experience of the processes. The duoethnographic approach enabled us to investigate and articulate some of the often invisible, complex, and even personally costly aspects of such curriculum development and implementation.

\section{A Duoethnographic Inquiry}

Inspired by duoethnographic inquiry developed by Richard Sawyer and Joe Norris (Norris \& Sawyer, 2004; Norris, 2008; Norris, Sawyer \& Lund, 2012; Sawyer \& Norris, 2013), we have collaboratively engaged in "critical dialogue" (Lund \& Veinotte, 2010, p. 5) for sharing and reinterpreting the complex layers and challenges of the work. According to Norris, Sawyer and Lund (2012), "Rather than uncovering the meanings that people give to their lived experiences, duoethnography embraces the belief that meanings can be and often are transformed through the research act” (p. 9). Thus, in this paper, readers bear witness to our collective narrative vulnerability as we publicly explore, expose, and reinterpret the work we often did in private. Sharing these stories and experiences uncovers and reinscribes the complexity and emotionality as well as the 
time-consuming, life-altering, and deeply challenging personal nature of such pedagogical curriculum work. This paper reminds of and demonstrates the ways that the "behind the scenes" work imagined and enacted by individuals and groups collaborating is critical to understanding a program's or curriculum's development and success, and more importantly to understanding more fully the ways such curriculum work always lives in the relational, messy world beyond the written page.

Duoethnography originates in dialogue (Sawyer \& Norris, 2013). While dialogue would most often today be understood as an oral conversation, the word dialogue was first used in Old French in the early $13^{\text {th }}$ century to refer to a "literary work consisting of a conversation between two or more persons" ("Dialogue," OED, n.d.). The Greek prefix "dia," often misinterpreted as meaning two, actually means through or across. Thus, duoethnography is a way of engaging in an "ethics of self-accounting” (Miller, as cited in Sawyer \& Norris, 2013, p. 291) together as a means for exploring an experience or phenomenon through conversation in such a way that new interpretations, meanings, and understandings become both necessary and possible. Our text follows the model of representation in duoethnography; that is, a text written as a dialogue between two people, without merging or subsuming two voices or perspectives (co-authors) into one coherent text, and without relying or drawing extensively on exterior voices or texts for substantiation. During the process, we questioned and provoked one another, and we had many face-to-face meetings where we took notes on conversations and our memories of the development and implementation of the field experience curriculum. We wrote many pieces after these meetings, which we exchanged with one another for further dialogue. Some of these pieces became the edited dialogue presented in this paper. Joe Norris (2008) describes the process and relationship between authors and between authors and readers in duoethnographic inquiry:

Each author of a duoethnographic piece is both the researcher and researched. The team employs storytelling to simultaneously generate, interpret, and articulate data. Stories beget stories-like interview questions - the stories enable the research-writing partners to recall other past events that they might not have remembered on their own. Their stories weave back and forth in juxtaposition to one another, creating a third space between the two into which readers may insert their own stories. (p. 234)

This rich methodology has enabled us to explore the curriculum implementation process and our own experiences of that in a manner that goes far beyond a curriculum product, getting to the heart of the complexity of the experience. While on the surface the product, and even the process, may have appeared mostly straightforward (and we wanted it to), what occurred behind the scenes was infinitely and unimaginably messy. It was full of surprises and joy, heartbreak and heartache, exhaustion and self-doubt, and sometimes conflict. Through narrating, sharing, responding to and re-editing the stories of our collaborative and individual experiences, we have been challenged to (re)understand our work together. Because the process of implementation itself was a great deal of complex work done in too little time, engaging in this writing project together has enabled us to reencounter the work we have done more reflectively and reflexively. 
While we attempted to engage in the profound challenge of narrating this complex story, we encountered the difficulty of truth telling. We wrote and shared many experiences, anecdotes, and stories that for ethical and professional reasons cannot be shared publicly, but we found the act of sharing them with one another, accompanied by much laughter and some tears, to be cathartic, and a way to build community and to process and leave some of the difficulties behind us. At the same time, we struggled with the idea of audience. There were (and are) many incidents and challenges that we feel would be important for someone to hear and care about, but we are not sure who that person is, and accordingly the silence of these stories and incidents has been borne by our bodies, in our personal lives, and by our families and friends.

\section{On Disclosing “Terrible Experiences”}

We offer this piece and methodology as both encouragement and example towards a means of engaging in what Jacques Derrida (1999) calls infinite close readings of our own situations, particularly those in which we find ourselves in leadership roles and responsible for making often difficult and/or ethical decisions that affect the work and lives of many other people. Derrida refers to his concept of undecidability to raise questions about how we know what to do when we find ourselves in situations where we are responsible to decide. How do we know what is the best or right decision, or the best or right way to proceed? Such undecidability was something we faced many times each day in our roles as Field Experience Curriculum Director and Field Experience Coordinator. We faced undecidability in working with various committees, in writing the curriculum documents, and in determining the final drafts, as well as when working with students and teachers, and when encountering colleagues who either supported or did not support the work.

Derrida describes undecidability not as inaction or paralysis in the face of a decision, but as the responsibility and necessity to choose. He insists that this is the beginning ground of all ethics and politics, and we propose this as the beginning ground of all pedagogical work, too. It is always a risk, yet we must decide what to do. Preservice teacher field experiences involve both ethics and politics and, we would add relationships to this list. Derrida (1999) writes:

I would argue that there would be no decision, in the strong sense of the word, in ethics, in politics, no decision, and thus no responsibility, without the experience of some undecidability. If you don't experience some undecidability, then the decision would simply be the application of the programme, the consequence of a premise or of a matrix. So a decision has to go through some impossibility in order for it to be a decision. If we knew what to do, if I knew in terms of knowledge what I have to do before the decision, then the decision would not be a decision. It would simply be the application of a rule, the consequence of a premise, and there would be no problem, there would be no decision. (p.66)

Derrida continues to say that decisions that depend on "responsibility" (p. 66) can be a "terrible experience" and that without going through this terrible experience "there would simply be a serene application of a programme of knowledge” (pp. 66-67). Derrida’s 
words offer some comfort and insight to those of us engaged in curriculum development or leadership in teacher education. Often, institutions (and universities and education in general), in order to function smoothly and to market their best "face" to the world, would like to pretend that these terrible experiences do not exist, or are not important or valuable. Certainly there is little time to experience them in the contemporary rush to measure up, to be top ranked, or to get things done efficiently and effectively. The "serene application of a programme of knowledge" seems more like what these institutions often ask of us. Indeed, it may be important that there is an appearance of a serene application and that those who lead know and have confidence in what they are doing. The dialogue in this paper, however, explores the shadow side of presenting the face of a serene application. Derrida helpfully reminds us that the institution is us (the institution is me, the institution is you), and that it is the terrible experiences and difficult decisions that we suffer far beyond what the institution would count or acknowledge as work that matter. Duoethnographic inquiry engages this difficult space of undecidability and terrible (and joyful) experiences.

\section{In the Beginning: Thinking Through Together}

\section{Jackie:}

When I was first asked by our Dean to take up the position of Field Experience Curriculum Director, I was told my role was to be the philosophical and scholarly energy behind the writing and implementation of a new curriculum. My imagination latched on to a vision of myself as curriculum theorist. I pictured myself sitting in a "professorishlooking” office, surrounded by books, drinking tea, staring out the window, and dreaming up a curriculum that would magically flow out into the world where it would be joyfully experienced by preservice teachers, partner teachers, and field instructors.

Four years later, this fantasy seems completely ridiculous. This work was neither a solitary nor a simple matter. Looking back, I understand that it was as necessarily and properly complicated and messy as any creative human and relational endeavour. The image of the philosopher lounging in my office was replaced by the reality of interminable rushing, meetings, consultations, late-night conversations, and uncountable, never-ending emails. It was punctuated by unfathomable, extraordinary, and unexpected emergencies, and by surprisingly joyful and creative experiences as well as new friendships and insights. I learned that implementing change and carrying the responsibility for leading it is exhausting, difficult work not only for the mind, but also for the body and spirit. The image of thinking alone was replaced by the image and practice of thinking together.

\section{Laurie:}

I was excited to collaborate in implementing a new approach to field experiences. Along with a colleague, I was responsible for field placements for our preservice teachers in each of the four semesters. This placement process involved a continuous correspondence with school administrations. It also involved the purposeful matching of preservice teachers with partner teachers, professional development for the partner teachers, and orientations for our field instructors. During the field experiences, we were available to support individual students, field instructors, partner teachers, or school 
administration in any way that was required. It was a demanding cycle, but the possibilities inherent in developing, introducing, and implementing a new field experience curriculum that provided our preservice teachers with a rich context to develop a deep understanding of best practices and that encouraged them to become committed professionals were appealing to me. I also learned that the work behind creating these possibilities could be demanding and solitary.

\section{Jackie:}

I'm interested that you use the word solitary. Although I refer to "thinking together" above, it's true for me also that much of this work was experienced as very lonely. For example, those many late nights writing and editing documents, and wondering if this was going in the right direction or if the learning experience would be as rich and challenging as we hoped, or if it would be received well by schools. The responsibility weighed heavily on me. However, despite these feelings of being alone, much of the work was defined and created through dialogue between us and between diverse partners in this work and that was exciting.

There was something completely remarkable about what we were asked to do: Create entirely new field experiences for preservice teachers. It was an exceptionally rare opportunity and privilege. I remember the thrill of the first Field Experience Committee who worked on the curriculum for semesters one and two during the fall of 2011. Much of the new B.Ed. course work was designed around collaboration, team learning, and topic integration. Everyone on the committee was excited by what it meant to bring such learning concepts into field experiences. We decided right away that we purposefully wanted the curriculum to break open the model of one preservice teacher with one partner teacher in one classroom supervised by one field instructor.

\section{Laurie:}

The design was a definite break from the model used in the past. In the first field experience, we were turning the model on its head. Preservice teachers were organized in cohorts to visit two school sites over two weeks. The intent was to experience life in an elementary school and in a middle or senior high school for a week each. The goal was to broaden the perspective of preservice teachers and to invite them to disrupt and reconsider their own experiences of school and their preconceived notions of what it might mean to be a teacher. Through online conversations with their peers and in seminar discussions, field instructors guided preservice teachers in engaging with scholarly readings and assignments to enhance their understanding of teaching. These changes were exciting and innovative and we thought everyone could not help but embrace them.

\section{Jackie:}

Institutional constraints were imposed on us: This introductory field experience was to be two weeks in the middle of the first semester. But still, we dreamed up crazy stuff in the beginning. It could go this way or that way. So many possibilities! We had to make decisions. Someone on the committee suggested that this experience could be an ethnographic field study in which preservice teachers inquired purposefully and collaboratively into the culture of schools. We decided to integrate the field experience 
into the Pragmatics of Learning and Teaching course as much as possible. Through the context of that course and their ethnographic study in schools for the two weeks in the middle of the term, students could be introduced to the collaborative scholarship of learning and teaching.

\section{Laurie:}

Yes, this was an exhilarating time! The meetings with our colleagues involved in developing and teaching the Pragmatics course were invigorating and thoughtful. So many wonderful ideas. We wanted to cement a clear and firm connection between the first field experience and our new Pragmatics course through course objectives and assignments that seamlessly supported the field philosophy. I was one of the coordinators for this new course and so had part of the responsibility for guiding the group discussion and encouraging consensus among my seven colleagues. As a new instructor, I was conscious of wanting to meet the challenge of this role. We talked about course objectives and assessment strategies, and the likely outcome of each decision. We thought about the themes we would like to take up and the readings that could support a thoughtful and meaningful investigation into teaching. We discussed the manner in which the preservice teachers would come to know themselves as learners and as emerging teachers, and we discussed how they might demonstrate this new sense of their professional identity and how their learning could be documented. These conversations were sometimes difficult as colleagues grappled with assumptions about our underlying philosophy for field experiences. This period of thinking through with colleagues gave us the opportunity to further define what we hoped would be essential elements of a field experience.

\section{Jackie:}

We then engaged in the work of thinking through together with teachers and school communities how this curriculum might live in their particular contexts. How could we place these large cohorts of students into the schools, not into individual classrooms, but into highly diverse school cultures where they would be acting as researchers rather than as what would traditionally be understood as 'student teachers'?

\section{Laurie:}

We knew that this shift from a more conventional field experience format was an imposition for the schools. Two groups of preservice teachers moving through a school, visiting classrooms, and inquiring into the particulars of the school's organization for two weeks was potentially disruptive and we did not expect that it would be readily embraced by every school site. Many educators wondered at first why preservice teachers were only engaged in observation and reflection.

This first placement was very complex and we spent a lot of time working through the details of organizing it for our students. But I think it was a worthwhile exercise. When our preservice teachers returned to campus to resume their classes, they were inspired and energized by the time they had spent in two completely different learning environments. As instructors, we were thrilled with the thoughtful observations and insightful reflections they had about their experiences. 


\section{Jackie:}

This initial field experience went better than we hoped, and was enacted in diverse and creative ways by many schools and field instructors. Overall, schools responded positively and embraced the concept of preservice teachers visiting their spaces as researchers. Schools were exceptionally eager to show off their programs and projects, and to provide unique experiences for the preservice teachers. One challenge that we had not anticipated in the initial implementation was that some students would be upset by this experience. They had an image in their mind of what it meant to be a student teacher. Some students challenged us, saying that they couldn't see the point, for example, of a secondary physics major going into a kindergarten class. However, what happened after the experience was a surprise! We had nearly 70 (of about 350) students request to change their program or major. Some were radical changes in subject discipline, or from secondary to primary, or vice versa. Many students expressed excitement about the diverse educational and teaching opportunities they witnessed, often quite different from what they imagined or what they themselves had experienced as learners.

\section{Working With Field Instructors and Partner Teachers: Resistance and Change}

\section{Laurie:}

Our work with field instructors was a key component of the new field experience program. We began by introducing and engaging both faculty and sessional instructors to the new curriculum. Often individuals expressed nostalgia for the old program and occasionally individuals resisted new ways of taking up fieldwork. Our relationships with these groups were contested. Our program goals were scrutinized, and our practice questioned. This was necessary, but exhausting work. We saw these individuals regularly on campus and we wanted our working relationship with them to remain collegial.

\section{Jackie:}

The instances of resistance were something that I didn't expect in the beginning. I imagined everyone would be as excited as I was. I was naïve in that sense. I like that you use the word necessary. That helps me! This prompted me to look up the word and the Latin root means "unavoidable." The dictionary tells me "the root sense is of that from which there is no evasion, that which is inevitable" ("Necessary" OED, n.d.). Looking back, it seems right that we encountered severe resistance. This challenged us to be thoughtful and watchful, to take good care of this new program, as well as to create space and time for dialogue with others, remembering that productive dialogue isn't always peaceful or about consensus.

Our first partner-teacher orientation comes to mind. This was for the second semester experience, which focused on preservice teachers engaging in initial questions of curriculum planning and student learning. Their assignment was to plan a series of learning experiences for a small group of students while inquiring into how they, as teachers, would come to know who those learners were and how they might best enter the topic or concept in relation to that knowledge. As we were sharing the curriculum, one of the participating teachers swore at us and left the session early saying she wasn't going to 
follow this curriculum and she knew what she was doing with student teachers and had done it for a long time. This moment was pedagogical for me and she became my teacher. I realized that my own enthusiasm for the project might have overshadowed imagining how it might be received. I am embarrassed to say that I forgot that some teachers weren't expecting, or prepared for, such a radical change in the ways we were asking them to mentor preservice teachers. They had been looking forward to doing it in a familiar way. Also, this curriculum was provoking some of them to question their own practices and, if they taught in a very traditional, teacher-centred way, it would be challenging to implement in their classroom (preservice teachers working with small groups, for example).

\section{Laurie:}

I agree that building and sustaining our relationships with partner teachers at this time was challenging. Creating a framework of relationships meant working with partner teachers and schools in a new way. We had to initiate a "transformation of participation" (Rogoff, 1994, p. 226) among school personnel who were familiar with working with us in a certain way. We devoted a great deal of time to creating positive partnerships with them. The method we had for doing this was organized on paper; we planned for numerous professional development workshops in all school jurisdictions so that we could meet with and talk with the individuals who would be working directly with our students. But in reality, the process was challenging.

We experienced anxiety in not knowing what could be done and when. On campus, we did not have full access to support staff knowledge or their time. As a result, we constantly conferred with each other, wondering if one of us had an answer to our questions, or knew about the process of finding out the answer to a question. Our engagement with our work felt fragmented, and at times, we felt frustrated. I think, though, that this discomfort is part of any new endeavour. It is to be expected.

\section{Jackie:}

Laurie, your thought that such resistance and challenges were necessary (no evasion!) is a sharp reminder that in any such endeavor of implementing (cultural) change, the process will always be shaped/marked by unavoidable and unexpected challenges, conflict, and resistance, and that the success of the project should not and cannot be measured either by the lack of resistance or by overcoming it because there is no such idyllic or utopian place of a perfect, conflict-free, project or process.

\section{Thoughts on Field Experiences as Scholarship}

\section{Laurie:}

The most worthwhile moments for me as a teacher are those in the company of others. I think it must be this way for most teachers. It is not the time we spend alone planning at our desk or the time spent in marking that stand out for us, but the exquisite moment when our conversation with someone else sparks a new idea, question, or connection. That moment stands out. It is not about who we are alone, but who we are in relationship to someone else. "Our goodness and our growth are inextricably bound to that of others we encounter. As teachers, we are as dependent on our students as they are 
on us" (Noddings, 1995, p. 196). This exquisite connection is at the heart of knowing for each of us and for teachers, at the core of best practice. In the act of connecting with each other, we can come to know the students and their strengths, and the students can come to know the world, each other, and themselves better.

\section{Jackie:}

I think this fits into an essential idea that we tried to work out: Field experiences, as teaching, could be conceptualized and experienced as a deep and relevant form of scholarship. How could we create an experience and culture where all aspects of schools, curriculum, learning, and teaching are open to questioning, critique, and historical study, and at the same time engage preservice teachers in the traditional kinds of activities they do in practicums, such as lesson planning? The purpose of this was to create a space also for inquiry into the future-into what schools might be, what teaching and learning might become, rather than having a space of cultural reproduction of what schools, or cultural images of schools, are (or were).

\section{Laurie:}

Maxine Greene (1993) suggested that teacher education was philosophy in the making... I've wondered how this statement applies to the process we were engaged in, but I think you have solved that mystery for me. We wanted preservice teachers to have opportunities to inquire into the entire nature of schools, curriculum, learning, and teaching, not just as they saw them, but into how they might wish them to be. This is education where understanding is in the making.

We discussed our assumptions about field experiences and we compared what field experiences looked like in other B.Ed. programs. We tried to imagine what the benefits and advantages would be for our preservice teachers in the creation of new course outcomes and thoughtful assignments that we hoped to connect back to the course work they had on campus. Our boundaries for philosophizing were constrained within the philosophy that already held us in our roles. So, this is something that we tested and tried to resolve the best that we could.

I think that in our field committee work we were trying to come to an agreement about how we could best give our preservice teachers the opportunity to come to know their students. We wanted our field instructors to know and work well with the preservice teachers. We tried to consider curriculum as one vehicle that would support these ideals and carefully planned field experiences embedded in the field curriculum as another. So maybe this was one of our core philosophical stances, that the opportunity and the possibility for preservice teachers to know their students (as learners) and themselves (as emerging teachers) was what we most wished for, while also knowing that this is an uncomfortable and uneven developmental shift (Britzman, 2007) that is not easily reconciled. We wanted our teacher education and the field experiences we were framing within our B.Ed. program to matter.

As you noted, Jackie, we hoped preservice teachers would make sense of and interpret the world that they were part of and imagine what might be possible. We wanted to embed this ideal of scholarship in the field experiences. And, this shift in thinking was 
possibly at the root of the resistance we encountered. The experiences are important, but without an interpretative stance (the space that you mention), the deeper meaning of the experience is missed.

\section{Jackie:}

Even as we tried to elevate the field experiences as a legitimate form of academic scholarship, it was often discounted (or uncounted). It raised the question again for me as an academic: What counts as valued and worthwhile work in a university? Or in faculties of education? Many senior professors gave their advice, very sincerely, that I should not be doing this fieldwork, and described in vivid detail the ways that it would ruin my career.

\section{Laurie:}

Field experience work seemed to be institutionally invisible. There was no money available for brochures, handouts, and so forth, to support our work. We bought refreshments ourselves for the workshops we conducted. We often struggled to get enough partner teachers for our students. Colleagues wondered aloud why we could not be more on top of the placement process. It was an effort to stay ahead of these tasks and to establish the kind of professional stance we wanted to bring to our work. The tension between the contradictory conceptualizations of field experience created problems. We viewed it as thoughtful, careful work that was dependent on understanding the importance of school setting, teacher expertise, and student academic characteristics, while others often saw it as a matching exercise. We believed that the development of preservice teacher knowledge is associated with the ability to establish relationships, to engage in collaborative work, and to participate in a school environment that is already in place, but is open to change.

\section{Negotiating Diverse Relationships}

\section{Jackie:}

Somehow, I didn't imagine how emotionally draining, or even devastating, this work would be. The students come with courageous hopes for their future as teachers. But for some, the road is difficult. Many unanticipated emergencies had to be handled immediately. Students sometimes arrived or emailed, angry and upset with the requirements of the curriculum. Some discovered that this career was not for them. Some became seriously ill. Some suffered the sudden death of someone dear to them. I remember one particular day when we met with a young woman who would not be continuing in the program. The meeting was so difficult. She wept. We cried together afterwards and our hearts were sore for days. To have the responsibility and power to make decisions that so powerfully affected the lives of others wounded my spirit and brought me no joy.

Yet, on the other side, there was much joy. In the hallways and elevators after field experiences, I'd ask them how it was and they'd say “Great!” Their faces were glowing and they would excitedly relate stories of their learning and experiences. They were so proud of themselves and I was proud of them. It feels good to have contributed to sending them into the world as teachers. 


\section{Laurie:}

I agree. We invested so much time in our relationships with the students. I think our work with partner teachers was also joyful. This work with teachers was most rewarding when done face-to-face in meetings when the new field curriculum was introduced to them. This direct link between their work and our work was visibly felt, like a shock of recognition, like friends of friends who meet for the first time. I think these meetings gave each of us energy to recommit to our work.

\section{Jackie:}

For me one of the most enjoyable parts of this work was connecting with teachers in the schools. We had developed a curriculum with outlined expectations and outcomes for preservice teachers, as well as course assignments that they were completing in and with their cohort and instructor. This was an entirely new conceptualization of the purpose and method of field experiences and needed to be communicated to the schools and partner teachers. In creating the curriculum, and in thinking about the complex character of schools and classrooms, we had tried to leave space for innovation in how the curriculum would be interpreted and lived. With each draft, we would try to imagine it in a kindergarten classroom or a high school chemistry classroom. With each iteration, our professional development sessions became more and more collaborative-more about engaging the field curriculum as a living document that required careful and ongoing interpretation in vastly diverse classroom contexts.

I remember feeling high with adrenalin after some of those sessions where as many as 60 teachers attended, hundreds of teachers over several days each semester. The teachers were excited to share their expertise, to work with the curriculum document to create the best possible learning experience for their preservice teacher(s). They arrived at the session after a long day of teaching, and we after a long day at the university, and yet somehow these conversations about the learning and mentorship of new teachers felt completely invigorating, fresh, and creative. I realized that innovation happens in many places and at many levels of an implementation, and that a great deal of freedom must exist for interpretive processes and experimentation to occur. When we invited teachers to participate creatively in these conversations with us, the curriculum documents began to come to life, and became much more than we had imagined. More exciting. More open. More possible.

\section{Laurie:}

Do you think this approach was effective? Looking back on the conceptualization that we had for the field curriculum, highlights to me how the initial goal of presenting the curriculum as an interpretable document has shifted. I found that some partner teachers wanted to have the parameters of the field placement explained to them and clearly defined. They were uncomfortable in making their own interpretations. And, when they did interpret the field course goals and course tasks and assignments, it was often with an impulse to give preservice teachers an experience similar to one that they had had as a student teacher. There was a familiarity about that stance that seemed appealing for them, I think. 


\section{Jackie:}

I think back to that teacher who stomped out of our first workshop swearing at us. Your question is very challenging for me. I still want to believe that an interpretive, generative, and creative approach to field curriculum implementation could work. And, I think it did work in some cases. I guess it constantly must come back to remembering that a perfect program or implementation is impossible, that challenges are necessary and will always be there, and that finding ways to work within such tensions and challenges is the real work. While some teachers desire strict parameters and want to know exactly what to do, and some others will ignore the curriculum completely no matter what, there are also those who embrace trying a new way. This is an exceptionally complex institutional space. It helps me to think of it ecologically. The more diversity there exists in an ecosystem, the more the ecosystem can be creative, responsive, and resilient. This reminds me that what we experienced is good! We don't want it to be a monoculture, although this is historically the institutional impulse of education. As humans, we have the habit of seeking the smooth and easy situation; if only we could get it right finally! Ha. Our experiences are a reminder that we will never solve all this difficulty or escape the complexity.

The cultural shift required to implement this collaborative model of preservice field experiences involved reconceptualizing the roles of all partners. This seems to me to be very difficult work that would take many more years than the time we had in these roles. Semester 3, in particular, which was oriented around students working in collaborative teams or partnerships with one another, provoked a deeply thoughtful and engaged response from many teachers. They connected this curriculum strongly with their own goals and the collaborative work with which they were already engaged. It was like what you said above, "A shock of recognition.” They presented ways for bringing preservice teachers into existing collaborations. They proposed exciting ideas... Can we do this? Can we do that? And, we were able to say "Yes" and "Yes" and "Yes." To feel this energy and excitement brought feelings of happiness and success. Feelings that all this hard work was worthwhile and was making a difference, connecting us to these classrooms, and to present and future teachers.

\section{Laurie:}

I thought that the changes in Semester 3 were the most exciting ones. The idea of preservice teachers collaborating to develop their practice in the same classroom was bold and innovative. However, that practice has been a victim of another change in how we do field, and it is one component no longer being continued. As preservice teachers stay with the same partner teacher now for Semester 3 and Semester 4, they must be placed within a classroom as an individual. It was a lovely idea that may come back some day.

\section{Jackie:}

I am really sad about this. That's exactly the institutionalized model we were trying to break open: Preservice teachers collaborating and inquiring in learning teams was one of the orienting ideas in the new B.Ed. program goals right from the beginning. What happened here demonstrates the enduring power of the individualistic mentality in 
education as an institution. Despite all we know about the power of collaboration, despite how excited teachers in the field were and how much they actually collaborate from day to day, this image of the individual teacher in the separate classroom working with students as individuals continued to dominate. It's such a strong historical force. In the case of our field experiences, it not only dominated but also "won." Perhaps there will be a way to try it again in the future.

\section{Some Closing Thoughts}

\section{Laurie:}

I like the ecological metaphor that you used to describe schools and learning environments. The idea that when greater diversity exists in a space, a greater possibility for creative, varied, and meaningful learning experiences to occur for our preservice teachers will also exist is an appealing one, and a hopeful one. The work of teacher preparation is contentious; many dimensions create the profile of a skilled professional teacher. The challenge for us was to identify and integrate the attributes that could be realized within our new program. We wanted our students to have an opportunity to develop a professional identity within a supportive context in which they would define what they believed about teaching and learning, and what they understood about the students, and in which to develop the deep understanding of themselves as an emerging teacher. This context rests on a supportive network of relationships between the university and the field, between partner teachers and preservice teachers, and between

preservice teachers and the learners in their classrooms. I think that our work was to build this context as best as we could and to establish a framework of relationships so that all of these connections could flourish.

Our time spent in conversation and collaborative work has helped to ground my thinking and guide me in my continued involvement in fieldwork. During the curriculum creation and implementation, we talked almost every day in person, by phone, or by email. We teased apart the essential elements of the field experience, tried to define our assumptions before they were challenged by someone else, and plotted a change of direction when not everything went as planned. We wondered together about the value of our work and about how it shaped our roles in the faculty. We pondered our professional identity in the midst of so much change. In our conversations, we could admit that we did not always feel heard or valued. These conversations helped me to recommit and to continue to engage in our common work. All of us will deal with changes in our professional lives and feel the pressure to accept and implement new practices and policies. This change can bring personal, intellectual, and professional growth, which is usually a struggle (Sarason, 2003). And, this idea of struggle takes us back to Derrida. The difficult decisions that we had to make, decisions linked to our responsibilities within the faculty, were a terrible experience, but a necessary struggle in order for field experiences to be re-imagined and to matter.

\section{Jackie:}

Indeed. I remember how many times we were talking late on a Saturday night, on the phone, in our pajamas. Or that I baked a lemon loaf or fresh bread late at night to bring to a meeting to offer some hospitality at a workshop since we had no funding 
available for nourishing guests. These were the invisible, un(ac)countable parts of this work. Engaging now in this collective writing - revisiting and recalling-teaches me the ways that the "behind the scenes" work, imagined and enacted by individuals and groups collaborating, might be critical to understanding a program's or curriculum's development and success, and more importantly, to understand more fully the ways such work in teacher education always lives in the relational, messy, and fleshy world beyond the tidy, written page. Sharing these stories and experiences now reminds me of the complex, emotional, time-consuming, life-altering, and deeply personal yet public nature of curriculum work.

It is difficult work. It is good work. 


\section{References}

Britzman, D. P. (2007). Teacher education as uneven development: Toward a psychology of uncertainty. International Journal Leadership in Education, 10 (1), 1-12.

Dialogue. (n.d.). Online Etymology Dictionary. Retrieved from http://www.etymonline.com/index.php?term=dialogue\&allowed_in_frame=0

Derrida, J. (1999). Hospitality, justice and responsibility. In R. Kearney \& M. Dooley (Eds.), Questioning ethics: Contemporary debates in philosophy (pp. 65-83). New York, NY: Routledge.

Greene, M. (1993). Diversity and inclusion: Toward a curriculum for human beings. Teachers College Record, 95(2), 211-221.

Lund, D. E., \& Veinotte, C. (2010). Researching a social justice course in a charter school: A duoethnographic conversation. in education, 6(2), 5-14.

Necessary. (n.d.). Online Etymology Dictionary. Retrieved from http://www.etymonline.com/index.php?allowed_in_frame=0\&search=necessary\& searchmode=none

Noddings, N. (1995). Philosophy of education. Boulder, CO: Westview Press.

Norris, J., \& Sawyer, R. (2004). Hidden and null curriculums of sexual orientation: A dialogue on the curreres of the absent presence and the present absence. In L. Coia et al. (Eds.), Democratic responses in an era of standardization (pp. 139159). Troy, NY: Curriculum and Pedagogy.

Norris, J. (2008). Duoethnography. In L. M. Given (Ed.), The SAGE encyclopedia of qualitative research methods (pp. 233-236). Los Angeles, CA: SAGE.

Norris, J., Sawyer, R. D., \& Lund, D (Eds). (2012). Duoethnography: Dialogic methods for social, health, and educational research. Walnut Creek, CA: Left Coast Press Inc.

Rogoff, B. (1994). Developing understanding of the idea of communities of learners. Mind, Culture, and Activity, 1(4), 209-229. doi:10.1080/10749039409524673

Sarason, S. B. (2003). Change, resistance, and reflection. In A. Lieberman (Ed.), The Jossey-Bass reader on teaching (pp. 103-110). San Francisco, CA: Jossey-Bass.

Sawyer, R. D., \& Norris, J. (2013). Duoethnography. New York, NY: Oxford University Press. 